\title{
EFFECT OF MITOMYCIN C ON THE CAPACITY OF E. COLI TO SUPPORT MULTIPLICATION OF $\phi \mathrm{A}^{1}$
}

\author{
AKIRA TAKETO \\ Department of Biochemistry, School of Medicine, Kanazawa University, \\ Takara-machi, Kanazawa 920
}

(Received March 12, 1975)

\begin{abstract}
Effect of Mitomycin C treatment on the host cell capacity for multiplication of $\phi \mathrm{A}$ was investigated, taking advantage of $\mathrm{Ca}^{2+}$-dependent transfection of the replicative-form DNA. In contrast to $u v r^{+}, u v r D$, and $u v r F$ strains, cells of $u v r A, u v r B$, or $u v r C$ mutant sufficiently supported the viral multiplication after treatment with $50 \mu \mathrm{g} / \mathrm{ml}$ of Mitomycin C. The host capacity of $u v r E$ strain showed an intermediate sensitivity to Mitomycin C. Plaque yield of $\phi \mathrm{A}$ in $\mathrm{rec}^{-}$strains was, as in $\mathrm{rec}^{+} u v r^{+}$hosts, markedly decreased by pretreatment with Mitomycin C. In contrast with DNA polymerase II, both polymerizing activity and $5^{\prime}-3^{\prime}$ exonuclease activity of DNA polymerase I were involved in host-cell reactivation for ultraviolet-irradiated replicative form. The capacity to develop $\phi \mathrm{A}$ of $\operatorname{polA}$, polA 107 , and res $A$ mutants was, like that of $\mathrm{pol}^{+}$or polB1 strains, conspicuously decreased upon treatment with the antibiotic. Effect of several radiomimetic agents on the host capacity was compared with that of Mitomycin C. In ultraviolet sensitivity of the host capacity, a small difference was observed between $u v r^{+}$bacteria and $u v r A$ mutant. Infectivity yield of Mitomycin C-treated replicative-form was not particularly affected by $u v r A$ mutation.
\end{abstract}

Whereas synthesis of bacterial DNA is selectively inhibited by $\mathrm{MC}^{2}(1)$, DNA synthesis induced by certain bacteriophages is rather refractory to the antibiotic (2). On the other hand, multiplication and DNA synthesis of $\phi \times 174$ in $E$. coli $\mathrm{C}$ or $E$. coli 15 are severely inhibited by MC treatment $(3,4)$. When, however, $\mathrm{HCR}^{-}$strain such as HF4704 is used as the host, multiplication of the

1 A part of this work was presented at the 47th Annual Meeting of the Japanese Biochemical Society, 1974. This paper is No. 9 in the series entitled "Sensitivity of Escherichia coli to Viral Nucleic Acid".

2 Abbreviations used: MC, Mitomycin C. RF, double-stranded replicative form DNA. SS, single-stranded viral DNA. HCR, host-cell reactivation. 4A-2Q-ran, 4-amino-2[(5-nitro2-furyl)vinyl]quinoline. PFU, plaque-forming unit. UV, ultraviolet light. 
virus proceeds normally without concomitant synthesis of host DNA (5). Taking advantage of this property of $\mathrm{HCR}^{-}$hosts, isotopic labeling studies of DNA replication in infected cells have been performed with several "mild" phages such as $\mathrm{S} 13, \mathrm{M} 13, \mathrm{fd}$, or $\lambda$. Regardless of practical applications, little is known about the differential action of $\mathrm{MC}$ on viral DNA synthesis in $\mathrm{HCR}^{+}$and $\mathrm{HCR}^{-}$cells. It seems apparently paradoxical that inhibition of viral growth caused by $\mathrm{MC}$ is counteracted by a defect in HCR function required for repair of viral as well as host DNA. In order to understand better the host functions necessary for viral replication, a survey was made on the $\mathrm{MC}$ effect on the growth of $\phi \mathrm{A}$ in various $E$. coli mutants deficient in DNA repair. Since $E$. coli strains used were mostly resistant to $\phi \mathrm{A}$, MC-pretreated or untreated bacteria were made competent by $\mathrm{Ca}^{2+}$ method and then challenged by the RF-DNA. The MC effect was clearly detected even in this transfection system (6).

\section{MATERIALS AND METHODS}

Bacteria and phage. Strain KMBL 1789 polA 107 (7) was furnished by Dr. B. W. Glickman. HF4704 uvrA (8), PK1620 recA uvrA, and ATR15 resAl (9) were obtained from Dr. M. Sekiguchi. Other sources of $E$. coli used were described previously $(10,11) . \phi \mathrm{A}$ is a single-stranded DNA phage immunologically related to $\phi \mathrm{X} 174(6)$.

Chemicals. MC was purchased from Sankyo Co., Tokyo, nalidixic acid was a gift from Daiichi Pharmaceutical Co., Tokyo, and 4A-2Q-ran was generously supplied by Dr. K. Miura. Phenethyl alcohol was obtained from Wako Pure Chemical Ind., Ltd., Osaka.

Treatment of host cells. Bacteria were grown in nutrient broth at $37^{\circ}$ with shaking and, when the optical density at $660 \mathrm{~nm}$ reached 0.5 , the culture was divided into two equal portions. To the one portion, MC (final concentration $50 \mu \mathrm{g} / \mathrm{ml}$ ) was added and shaken further for $10 \mathrm{~min}$ at $37^{\circ}$. The cultures were chilled, centrifuged, and the collected cells were suspended in chilled $50 \mathrm{mM} \mathrm{CaCl}$. Treatment with $4 \mathrm{~A}-2 \mathrm{Q}-\operatorname{ran}(5 \mu \mathrm{g} / \mathrm{ml})$ was done similarly. When bacteria were to be treated with nalidixic acid $(50 \mu \mathrm{g} / \mathrm{ml})$ or phenethyl alcohol $(0.3 \%)$, incubation was extended to $25 \mathrm{~min}$. For UV irradiation, cells were suspended in chilled $50 \mathrm{mM} \mathrm{CaCl}_{2}$ and irradiated, for the indicated time, with a $15 \mathrm{~W}$ Mazda germicidal lamp at a distance of $25 \mathrm{~cm}$.

Infectious DNA and transfection. The SS and RF DNA of $\phi \mathrm{A}$ and $\phi \mathrm{X} 174$, nonlabeled or labeled with ${ }^{14} \mathrm{C}$-thymine, were prepared as described previously (10). Bacteria were made competent by $\mathrm{CaCl}_{2}$ method as described elsewhere (12). For transfection assay, $0.1 \mathrm{ml}$ of the cell suspension $\left(\mathrm{OD}_{660}=15\right)$ in chilled $50 \mathrm{~mm}$

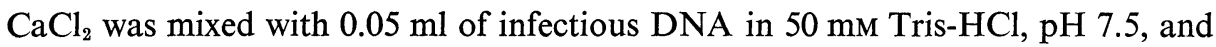
kept at $0^{\circ}$ for $20 \mathrm{~min}$. Without heat pulse, the infected cells were diluted with chilled $50 \mathrm{mM} \mathrm{CaCl}_{2}$ and plated with the indicator bacteria (strain $\mathrm{C}$ ), at least in 
duplicate. Omission of a heat-pulse step simplified the assay method without reducing infectivity yield of the DNA.

$M C$ treatment of $R F . \quad \phi \mathrm{A} R F$ labeled with ${ }^{14} \mathrm{C}$-thymine was mixed at room temperature with $50 \mu \mathrm{g} / \mathrm{ml}$ of $\mathrm{MC}$ and $200 \mu \mathrm{g} / \mathrm{ml}$ of sodium hydrosulfite in a total volume of $0.5 \mathrm{ml}$. Q gas was bubbled through all the components and the reaction mixture. Control mixture without $\mathrm{MC}$ was run in parallel. After $5 \mathrm{~min}$, the mixture was passed through a CPG-10 column $(0.5 \times 26 \mathrm{~cm})$, using $50 \mathrm{~mm}$ Tris- $\mathrm{HCl}, \mathrm{pH} 7.5$, and 10 drops of the filtrate were collected per fraction. Peak of the labeled RF appeared at fraction 14 and MC (detected by bacteriocidal activity) was eluted around fraction 25 .

\section{RESULTS}

\section{$M C$ action on viral growth}

Infectivity yield of $\phi \mathrm{A}$ or $\phi \mathrm{X} 174 \mathrm{RF}$ in $E$. coli $\mathrm{C}$ was greatly reduced by

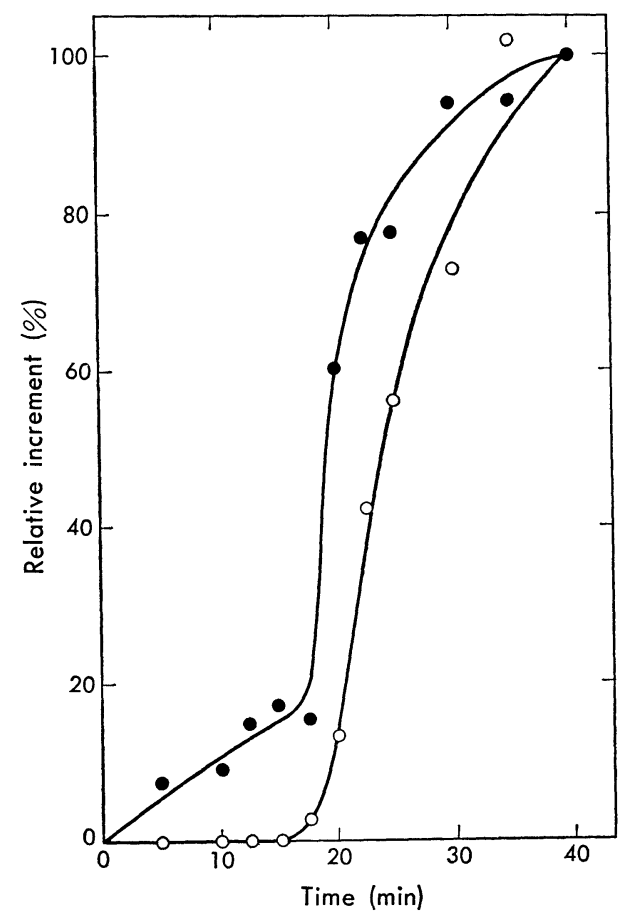

Fig. 1. Effect of $\mathrm{MC}$ on the growth of $\phi \mathrm{A}$ in $E$. coli $\mathrm{C}$.

Log phase cells of $E$. coli $\mathrm{C} u v r^{+}$in broth were infected with $\phi \mathrm{A}$ at a multiplicity of 0.1 . At the indicated time, aliquot of the culture was transferred to a broth containing $50 \mu \mathrm{g} / \mathrm{ml}$ of MC and shaken at $37^{\circ}$. Mature phage yield was determined $40 \mathrm{~min}$ after infection (๑). In parallel, amount of intracellular phage was determined immediately before addition of $\mathrm{MC}(\mathrm{O})$. 
incubating the bacteria with $50 \mu \mathrm{g} / \mathrm{ml}$ of $\mathrm{MC}$ for $10 \mathrm{~min}$, before $\mathrm{Ca}^{2+}$ treatment or after completion of RF uptake. Similar inhibition of the viral growth was observed when SS molecule was used as the transfecting DNA. In normal cellwhole virus system, MC exerts its inhibitory effect even in the late eclipse phase (Fig. 1). These results suggest that replication of progeny RF, and not parental RF formation, is blocked by the antibiotic.

\section{Host capacity of uvr mutants treated with $M C$}

As several $u v r$ functions are known to participate in HCR process of UVirradiated $\phi \mathrm{A} \mathrm{RF}(10,11)$, effect of $\mathrm{MC}$ on the capacity to support $\phi \mathrm{A}$ growth was investigated first with various $u v r$ mutants. In $u v r^{+}$strains, the host capacity (expressed by the relative yield of transfectants) was generally reduced to less than $10^{-3}$ by pretreatment with $50 \mu \mathrm{g} / \mathrm{ml}$ of MC. On the other hand, $u v r A, B$ or $C$ mutants of both $\mathrm{N}$ and $\mathrm{AB}$ series retained nearly normal capacity to propagate $\phi \mathrm{A}$, after MC treatment (Table 1). While $u v r D$ function was involved in HCR,

Table 1. Effect of MC treatment on the host capacity of $u v r$ strains.

\begin{tabular}{|c|c|c|c|}
\hline \multirow{2}{*}{ Strain } & \multicolumn{3}{|c|}{ Plaque yield (PFU/ml) } \\
\hline & Untreated & MC-treated & $\begin{array}{c}\text { MC-treated/ } \\
\text { Untreated }\end{array}$ \\
\hline W3623uvr $r^{+}$ & $1.6 \times 10^{5}$ & $<1.0 \times 10^{1}$ & $6.2 \times 10^{-5}$ \\
\hline N17-9 $u v r A$ & $2.1 \times 10^{5}$ & $7.4 \times 10^{4}$ & $3.5 \times 10^{-1}$ \\
\hline N3-1 $u v r B$ & $1.8 \times 10^{4}$ & $1.3 \times 10^{4}$ & $7.2 \times 10^{-1}$ \\
\hline $\mathrm{N} 17-7 u v r C$ & $6.0 \times 10^{3}$ & $4.8 \times 10^{3}$ & $8.0 \times 10^{-1}$ \\
\hline $\mathrm{N} 14-4 u v r D$ & $1.3 \times 10^{4}$ & $<1.0 \times 10^{1}$ & $<7.7 \times 10^{-4}$ \\
\hline $\mathrm{AB} 1157 u v r^{+}$ & $2.3 \times 10^{5}$ & $<1.0 \times 10^{2}$ & $<4.4 \times 10^{-4}$ \\
\hline $\mathrm{AB} 1886 u v r A$ & $5.1 \times 10^{4}$ & $3.4 \times 10^{4}$ & $6.7 \times 10^{-1}$ \\
\hline $\mathrm{AB} 1885 u v r B$ & $2.3 \times 10^{5}$ & $1.3 \times 10^{5}$ & $5.7 \times 10^{-1}$ \\
\hline $\mathrm{AB} 1884 u v r C$ & $8.9 \times 10^{5}$ & $3.4 \times 10^{5}$ & $3.8 \times 10^{-1}$ \\
\hline CT-2 $u v r^{+}$ & $2.6 \times 10^{6}$ & $8.0 \times 10^{1}$ & $3.1 \times 10^{-5}$ \\
\hline HF4704 $u v r A$ & $9.3 \times 10^{5}$ & $5.0 \times 10^{5}$ & $5.4 \times 10^{-1}$ \\
\hline ES108 mutU4(uvrE) & $3.3 \times 10^{5}$ & $2.8 \times 10^{4}$ & $8.5 \times 10^{-2}$ \\
\hline PC1249 uvrF & $5.9 \times 10^{5}$ & $<1.0 \times 10^{1}$ & $<1.7 \times 10^{-5}$ \\
\hline
\end{tabular}

Bacteria preincubated with or without $\mathrm{MC}$ were treated with $\mathrm{CaCl}_{2}$ challenged with $\phi \mathrm{A} R \mathrm{R}$ and then plaque yield was determined by infective center assay. The number of transfected cells represents relative host capacity for $\phi \mathrm{A}$.

the capacity of N14-4 uvrD was no more resistant to MC than were $u v r^{+}$bacteria. MC treatment significantly reduced the yield of transfectants in ES108 mutU4 $\left(=u v r E\right.$ ), but the decrement was much less than in $u v r^{+}$strains. HCR ability of $u v r F$ mutant was as high as that of $u v r^{+}$cells and the host capacity of $u v r F$ strain was quite sensitive to $\mathrm{MC}$. 
Host capacity of rec mutants treated with $M C$

Recombination deficient strains are generally sensitive to UV irradiation

Table 2. Effect of MC treatment on the host capacity of rec strains.

\begin{tabular}{lccc}
\multicolumn{1}{c}{ Strain } & \multicolumn{3}{c}{ Plaque yield (PFU/ml) } \\
\cline { 2 - 4 } & Untreated & MC-treated & $\begin{array}{c}\text { MC-treated/ } \\
\text { Untreated }\end{array}$ \\
\hline AB2463 rec $A$ & $2.1 \times 10^{5}$ & $<1.0 \times 10^{1}$ & $4.8 \times 10^{-5}$ \\
PK1620 rec $A$ uvrA & $9.1 \times 10^{5}$ & $3.5 \times 10^{5}$ & $3.8 \times 10^{-1}$ \\
AB2470 recB & $6.6 \times 10^{5}$ & $1.5 \times 10^{2}$ & $2.3 \times 10^{-4}$ \\
JC6720 recBC & $8.9 \times 10^{5}$ & $4.5 \times 10^{2}$ & $5.0 \times 10^{-4}$ \\
JC5183 recBC $\operatorname{sbc} A$ & $2.0 \times 10^{6}$ & $1.3 \times 10^{3}$ & $6.5 \times 10^{-4}$ \\
JC7623 recBC $\operatorname{sbcB}$ & $2.5 \times 10^{5}$ & $4.0 \times 10^{1}$ & $1.6 \times 10^{-4}$ \\
JC8287 recBC $x o n A$ & $2.8 \times 10^{4}$ & $3.6 \times 10^{2}$ & $1.4 \times 10^{-2}$ \\
PC0297 recG & $2.8 \times 10^{5}$ & $1.6 \times 10^{2}$ & $5.7 \times 10^{-4}$ \\
PC1250 recH & $2.2 \times 10^{5}$ & $6.0 \times 10^{1}$ & $2.7 \times 10^{-4}$ \\
\hline
\end{tabular}

The conditions are the same as in Table 1.

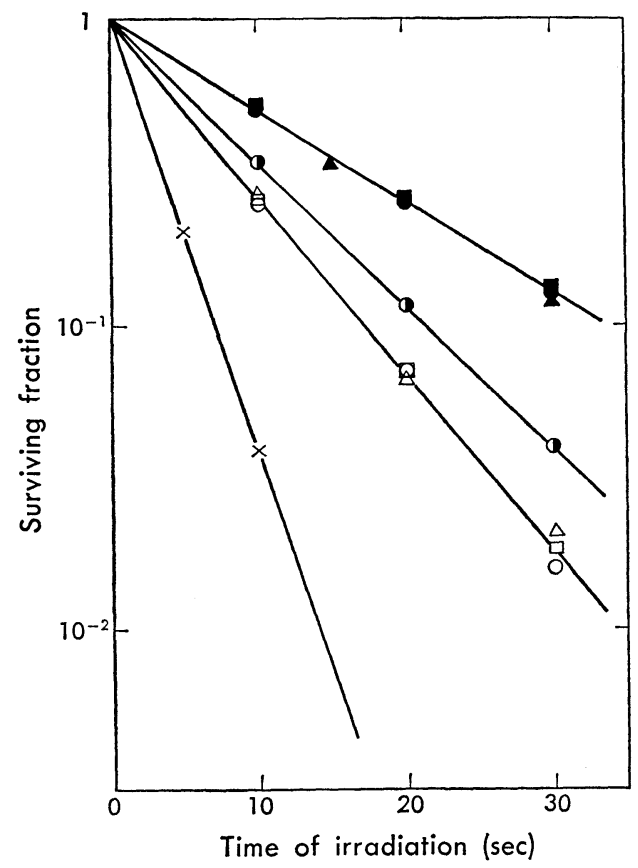

Fig. 2. HCR of UV-irradiated $\mathrm{RF}$ in $\mathrm{Ca}^{2+}$-treated cells.

$\phi \mathrm{A}$ RF was UV-irradiated with a $15 \mathrm{~W}$ germicidal lamp at $25 \mathrm{~cm}$, in $50 \mathrm{~mm}$ Tris$\mathrm{HCl}, \mathrm{pH} \mathrm{7.5}$, and the infectivity was determined on $\mathrm{Ca}^{2+}$-treated cells of strain $\mathrm{C} u v r^{+}$ $(\bullet)$; P3478 polA1 (O); N611 polA $(\square)$; ATR15 resA1 $(\triangle)$; HMS85 polB1 (ロ); JC8287

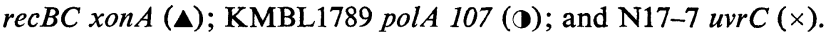


but retain HCR ability to UV-irradiated phages. As seen in Table 2, most rec strains tested were deprived of the host capacity by the MC treatment. However, the host capacity of $\operatorname{rec} A$ uvrA double mutant was, like $\mathrm{rec}^{+} u v r A$ strains, rather resistant to the antibiotic. The ability of JC8287 recBC xon $A$ to support $\phi \mathrm{A}$ growth was somewhat less affected by $\mathrm{MC}$ as compared with wild type or $\operatorname{rec} B C$ $s b c B$ bacteria. HCR function of the $\operatorname{rec} B C$ xon $A$ strain is normal (Fig. 2) and significance of the small decrease in MC sensitivity is unknown.

Effect of MC on the host capacity of pol, res, or rep mutants

It has been demonstrated that UV-irradiated $\phi \mathrm{A}$ RF exhibits lower survival in spheroplasts of polA mutants (10). As shown in Fig. 2, decreased HCR ability of polA mutants is more clearly detectable in $\mathrm{Ca}^{2+}$-dependent transfection system. Recently, HeIJNEKer et al. (13) and GLICKMAN et al. (14) have suggested that 5'-3' exonuclease activity of DNA polymerase I is deficient in polA 107. HCR activity of polA 107 and resA1 is also compared in Fig. 2. While survival of UV-irradiated $\phi \mathrm{A}$ RF was as low in resA1 mutant as in polA strains, HCR activity was less affected by polA 107 mutation.

In order to clarify whether the MC sensitivity was affected by any polymerizing and/or exonucleolytic activities of DNA polymerase I, the host capacity of several pol or res mutants was compared before or after the MC treatment. The data presented in Table 3 indicate that genetic deficiency in DNA polymerase I does not render the host capacity of these cells resistant to MC. HCR ability for UV-irradiated $\phi$ A RF was not affected at all by polB1 mutation (Fig. 2) and pretreatment with $\mathrm{MC}$ greatly reduced the host capacity of the mutant devoid of DNA polymerase II. On the other hand, $\phi \mathrm{A}$ as well as $\phi \mathrm{X} 174$ cannot grow in rep mutant of E. coli $(11,15)$. Pretreatment of rep strain with MC did not restore the host capacity at all.

Table 3. Effect of MC treatment on the host capacity of pol, res and rep strains.

\begin{tabular}{lccc}
\multicolumn{1}{c}{ Strain } & \multicolumn{3}{c}{ Plaque yield (PFU/ml) } \\
\cline { 2 - 4 } & Untreated & MC-treated & $\begin{array}{c}\text { MC-treated/ } \\
\text { Untreated }\end{array}$ \\
\hline W3110 wild & $3.3 \times 10^{3}$ & $<5.0 \times 10^{0}$ & $<1.6 \times 10^{-3}$ \\
P3478 polA1 & $3.0 \times 10^{3}$ & $<5.0 \times 10^{0}$ & $<1.7 \times 10^{-3}$ \\
N611 polA & $1.5 \times 10^{5}$ & $<1.0 \times 10^{1}$ & $<6.6 \times 10^{-5}$ \\
ATR15 resA1 & $1.6 \times 10^{5}$ & $<2.0 \times 10^{1}$ & $<1.4 \times 10^{-4}$ \\
KMBL1789 polA 107 & $1.2 \times 10^{5}$ & $2.3 \times 10^{2}$ & $1.9 \times 10^{-3}$ \\
HMS85 polB1 & $1.8 \times 10^{4}$ & $<1.0 \times 10^{1}$ & $<5.6 \times 10^{-4}$ \\
D32 rep3 & 0 & 0 & - \\
\hline
\end{tabular}

The conditions are the same as in Table 1. 
Effect of several radiomimetic agents on the host capacity

In $E$. coli, MC selectively inhibits DNA synthesis, causes degradation of DNA, induces $\lambda$ phage development and exerts a mutagenic action. These properties are to a certain extent shared with $\mathrm{UV}$, nitrofuran compounds, or nalidixic acid. Therefore, effect of these compounds on the host capacity of $u v r^{+}$and $u v r A$ strains was subsequently examined. Although neither DNA degradation nor induction of lysogenic phage was observed with phenethyl alcohol, this DNA-synthesis inhibitor was also tested. As shown in Fig. 3, the host capacity of $u v r^{+}$bacteria is somewhat more sensitive than that of $u v r A$ mutant to UV. The difference be-

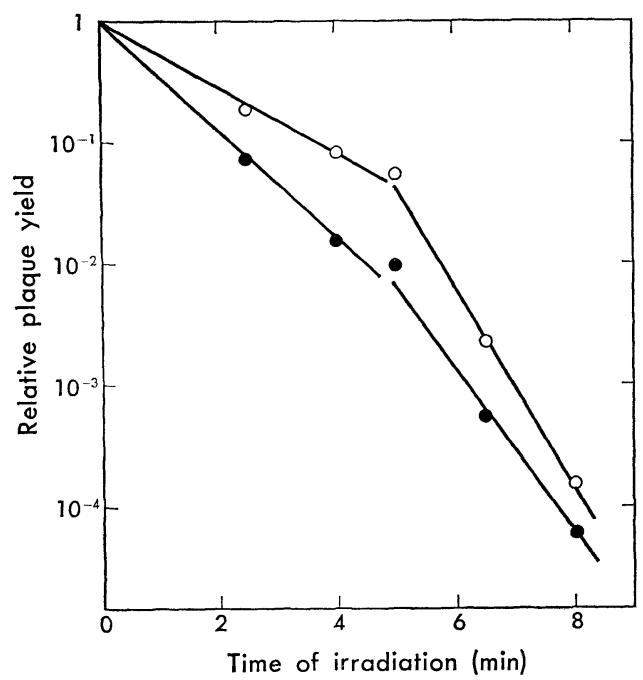

Fig. 3. UV sensitivity of the host capacity for $\phi \mathrm{A} R \mathrm{RF}$.

Cells of E. coli C $u v r^{+}(\bullet)$ or HF4704 uvrA (O) were irradiated with UV for the indicated time and the capacity of the bacteria was determined by $\mathrm{Ca}^{2+}$-dependent transfection.

Table 4. Capacity of $u v r^{+}$and $u v r A$ hosts treated with agent affecting DNA synthesis.

\begin{tabular}{ccc}
\hline \multirow{2}{*}{ Treatment with } & \multicolumn{2}{c}{ Relative plaque yield on } \\
\cline { 2 - 3 } & CT-2 $u v r^{+}$ & HF4704 uvr $A$ \\
\hline None (untreated control) & 1 & 1 \\
& $\left(3.2 \times 10^{6} \mathrm{PFU} / \mathrm{ml}\right)$ & $\left(2.8 \times 10^{6} \mathrm{PFU} / \mathrm{ml}\right)$ \\
4A-2Q-ran ${ }^{a}(5 \mu \mathrm{g} / \mathrm{ml})$ & $5.5 \times 10^{-3}$ & $1.0 \times 10^{-2}$ \\
Nalidixic acid ${ }^{b}(50 \mu \mathrm{g} / \mathrm{ml})$ & $2.2 \times 10^{-1}$ & $4.0 \times 10^{-2}$ \\
Phenethyl alcohol $^{b}(0.3 \%)$ & $5.3 \times 10^{-2}$ & $6.7 \times 10^{-2}$ \\
\hline
\end{tabular}

$a$ Growing culture was treated for $10 \mathrm{~min}$ at $37^{\circ}$.

$b$ Growing culture was treated for $25 \mathrm{~min}$ at $37^{\circ}$. 
tween the two strains was, however, rather small as compared with a marked difference in their MC sensitivity. In addition, the capacity of $u v r A$ strain was as sensitive as that of $u v r^{+}$cells to pretreatment with 4A-2Q-ran, nalidixic acid, or phenethyl alcohol (Table 4).

\section{Host capacity for MC-treated RF}

Although natural form is quite inert, chemically or enzymically reduced $\mathrm{MC}$ reacts with DNA and cross-links its complementary strands (16). In the present experiments, amount of activated MC remaining in washed cells seems to be small, and yet it may be sufficient for cross-linking of RF DNA. The reduced infectivity in MC-treated $u v r^{+}$strains may then be derived from break down of cross-linked $\mathrm{RF}$ rather than inactivation of host functions. In order to exclude the possibility, $\phi \mathrm{A}$ RF was reacted with activated MC in vitro, and infectivity of the treated RF was compared with that of untreated control on $u v r^{+}$bacteria and $u v r A$ mutant. As seen in Table 5, the host capacity for MC-treated RF was not significantly different between $u v r^{+}$and $u v r A$ strains.

Table 5. Capacity of $u v r^{+}$and $u v r A$ hosts for $\phi \mathrm{A}$ RF treated with activated MC.

\begin{tabular}{lccc}
\hline \multirow{2}{*}{ System } & \multicolumn{3}{c}{ Plaque yield (PFU/ml) on } \\
\cline { 2 - 4 } & \multicolumn{2}{c}{ CT-2 $u v r^{+}$} & HF4704 uvrA \\
\hline Untreated control & $9.8 \times 10^{5}$ & $(100)$ & $2.8 \times 10^{5} \quad(100)$ \\
Complete & $9.0 \times 10^{5}$ & $(92)$ & $2.3 \times 10^{5}(82)$ \\
Minus MC & $9.5 \times 10^{5}$ & $(97)$ & $2.7 \times 10^{5}(96)$ \\
\hline
\end{tabular}

After reaction in vitro with reduced $\mathrm{MC}, \phi \mathrm{A} \mathrm{RF}$ (labeled with ${ }^{14} \mathrm{C}$-thymine) was reisolated by gel filtration through a CPG-10 column and the infectivity was determined. Before infectivity assay, amount of the RF samples was standardized by its radioactivity.

\section{DISCUSSION}

Repair of UV-irradiated $\phi \mathrm{A}$ RF requires host gene products of $u v r A, u v r B$, $u v r C, u v r D, u v r E(m u t U)$, and $\operatorname{pol} A(\operatorname{res} A)(10,11$, and present data). Apparently, $u v r F$ function is dispensable for $\mathrm{HCR}$ of the irradiated $\mathrm{RF}$ and MC-treated $u v r F$ mutant is unable to support $\phi \mathrm{A}$ multiplication. In $u v r A$ or $B$ mutants, repair of cellular DNA is blocked at incision process owing to the deficiency of UV-endonuclease, while defects in $u v r C$ mutant is probably in subsequent excision step (1719). Regardless of these differences, either $u v r A, B$, or $C$ mutants sufficiently support the multiplication of $\phi \mathrm{A}$, even after severe treatment with $\mathrm{MC}$. It seems noteworthy that T4 endonuclease V-dependent reactivation of UV-irradiated $\phi \mathrm{A}$ or $\phi \mathrm{X} 174 \mathrm{RF}$ occurs in $u v r C$ mutant as well (10). MC-sensitivity of the host capacity of $u v r E$ strain was higher than that of $u v r A, B$, or $C$ strains, but considerably low compared with that of $u v r^{+}$bacteria. The role of $u v r E$ gene product 
in DNA repair is presently unknown. As in $u v r^{+}$cells, the capacity to support $\phi$ A multiplication was sensitive to $\mathrm{MC}$ in $u v r D$ or polAl strains. Furthermore, MC sensitivity of the host capacity was not decreased in resAl or polA $107 \mathrm{mu}$ tants, suggesting that neither $5^{\prime}-3^{\prime}$ exonuclease activity nor polymerizing activity of DNA polymerase $I$ is related with the MC effect. On the other hand, HCR ability of strains such as $\operatorname{pol} B, \operatorname{rec} A, \operatorname{rec} B C, \operatorname{rec} G$, or $\operatorname{recH}$ was as high as that of wild type bacteria and these strains lost their capacity for $\phi \mathrm{A}$ upon $\mathrm{MC}$ treatment.

Extensive breakdown of cellular DNA observed in MC-treated $u v r^{+}$bacteria does not occur in $u v r$ mutants, which are much more sensitive to MC than are $u v r^{+}$strains (20). It has been shown that $u v r$ functions are involved in the excision repair of Mitomycin-induced defect of E. coli DNA (17).

Occurrence of replication of $\phi \mathrm{A}$ and $\phi \mathrm{X} 174$ in MC-treated $u v r A, B$, or $C$ hosts suggests the following possibilities: (i) The viral DNA may be far less cross-linked by MC owing to its small size, (ii) the cross-linked viral DNA may be repaired by host functions other than $u v r$ system, and (iii) the MC-induced damage in viral DNA might be tolerated or bypassed in replication process. While the viral growth was inhibited in MC-pretreated washed $u v r^{+}$hosts, infectivity yield of $\phi \mathrm{A}$ RF reacted with MC in vitro was not different between $u v r^{+}$ bacteria and $u v r A$ strain. In addition, LINDQvisT and SinSHEIMER (5) showed that growth of $\phi \mathrm{X} 174$ proceeded in a $\mathrm{HCR}^{-}$strain even when $\mathrm{MC}$ was present during the entire process of infection. These data thus suggest that viral DNA per se is not a direct target of the antibiotic.

Replication of minute viruses such as $\phi \mathrm{A}$ or $\phi \mathrm{X} 174$ depends considerably on various cellular functions coded by host DNA. However, causal relationship between DNA degradation and loss of the host capacity is not clear because cellular enzymes and proteins required for viral growth may function even after MC treatment. Breakdown of host DNA might cause some structural alterations in replication apparatus common to bacteria and virus. In connection with DNA degradation, it seems noteworthy that the capacity of $\operatorname{rec} A u v r A$ mutant was, unlike $\mathrm{rec}^{+}$or $\operatorname{rec} A$ strains, not affected by MC.

Between $u v r^{+}$and $u v r A$ bacteria, a difference was observed in UV sensitivity of the host capacity for $\phi \mathrm{A}$. This difference, though significant, was rather small compared with MC sensitivity. These results may suggest that more than breakdown of host DNA is involved in the MC effect. If viral DNA replication is dependent on some enzymes or sites involved in host DNA repair, MC treatment might reduce plaque yield in $u v r^{+}$bacteria, through competition between host DNA repair and viral replication.

I am grateful to Dr. M. Sekiguchi for providing bacterial strains and for stimulative discussion.

\section{REFERENCES}

1) S. Shiba, A. Terawaki, T. Taguchi, and J. Kawamata, Nature, 193, 1056 (1959). 
2) M. Sekiguchi and Y. TAKagi, Biochim. Biophys. Acta, 41, 434 (1960).

3) A. TAKeto, J. Biochem. (Tokyo), 54, 520 (1963).

4) K. Matsubara, A. Taketo, and Y. Takagi, J. Biochem. (Tokyo), 54, 225 (1963).

5) B. H. Lindevist and R. L. Sinsheimer, J. Mol. Biol., 30, 69 (1967).

6) A. TAKeto, J. Biochem. (Tokyo), 75, 951 (1974).

7) B. W. Glickman, C. A. van Sluis, H. L. Heijneker, and A. Rörsh, Mol. Gen. Genet., 124, 69 (1973).

8) B. H. Lindevist and R. L. Sinsheimer, J. Mol. Biol., 28, 87 (1967).

9) T. KATO and S. Kondo, J. Bacteriol., 107, 871 (1970).

10) A. Taketo, S. Yasuda and M. Sekiguchi, J. Mol. Biol., 70, 1 (1972).

11) A. TAketo and S. Kuno, J. Biochem. (Tokyo), 75, 59 (1974).

12) A. TAketo, J. Biochem. (Tokyo), 72, 973 (1972).

13) H. L. Heijneker, D. J. Ellens, R. H. Tjeerds, B. W. Glickman, B. van Dorp, and P. H. Pouwels, Mol. Gen. Genet., 124, 83 (1973).

14) B. W. Glickman, C. A. van Sluis, G. van der MaAs, and A. Rörsch, J. Bacteriol., 114, 951 (1973).

15) D. T. Denhardt, M. Iwaya, and L. L. Larison, Virology, 49, 486 (1972).

16) V. N. IYer and W. Szybalski, Science, 145, 55 (1964).

17) N. Otsuji and I. Murayama, J. Bacteriol., 109, 475 (1972).

18) T. KATO, J. Bacteriol., 112, 1237 (1972).

19) A. Braun and L. Grossman, Proc. Natl. Acad. Sci. U.S., 71, 1838 (1974).

20) R. P. Boyce and P. Howard-Flanders, Z. Vererbungsl., 95, 345 (1964). 